\title{
Penyusunan Rancangan Desain Dokumen Dan Laporan Keuangan Jujur Ministry Menuju Transparansi Keuangan
}

\author{
Santy Setiawan ${ }^{1}$, Se Tin $^{2}$, Aurora Angela ${ }^{3}$, Sondang Mariani Rajagukguk ${ }^{4}$, Candra Sinuraya ${ }^{5}$, Anthonius ${ }^{6}$, \\ Barnabas Tridig S. ${ }^{7}$, Frederick Ruben Hartanto ${ }^{8}$, Stefani Chendana ${ }^{9}$ \\ Program Studi Akuntansi, Universitas Kristen Maranatha \\ Prof. Drg. Surya Sumantri No. 65, Bandung \\ 1santy_jc@yahoo.com \\ 2setin2005@yahoo.com \\ 3aurora.angela@maranatha.edu \\ 4rsondang@gmail.com \\ 5candra.sinuraya@eco.maranatha.edu \\ 6 anthonius@eco.maranatha.edu \\ 7barnabas.ts@eco.maranatha.edu \\ 81951009@eco.maranatha.edu \\ 91951032@eco.maranatha.edu
}

\begin{abstract}
Abstrak - Pandemi Covid 19 yang melanda saat ini berimbas pada keadaan perekonomian Indonesia, bahkan mempengaruhi kehidupan ekonomi masyarakat Indonesia. Banyak masyarakat Indonesia saat ini yang kehilangan pekerjaan dan hidup di bawah garis kemiskinan. Jujur Ministry didirikan dengan maksud untuk membantu masyarakat yang terkena dampak Covid 19 dengan memberikan sarapan gratis bagi masyarakat yang tidak mampu, dan dalam jangka panjang memiliki rencana untuk memberikan bantuan dalam bidang pendidikan dan renovasi rumah. Pendiri Jujur Ministry memiliki keinginan untuk memiliki pencatatan laporan keuangan yang transparan untuk memberikan pertanggungjawaban kepada para donatur. Budaya kejujuran dan rasa kemanusiaan yang melatarbelakangi diselenggarakannya pengabdian masyarakat kepada Jujur Ministry. Tujuan pengabdian masyarakat yang dilakukan oleh tim pengabdi yang terdiri dari dosen Program Studi Akuntansi di Fakultas Bisnis Universitas Kristen Maranatha adalah membantu dalam pembuatan desain kegiatan, dokumen akuntansi dan laporan keuangan untuk Jujur Ministry. Pengabdian masyarakat menggunakan metode wawancara kepada pendiri Jujur Ministry dan dilakukan secara bertahap mulai dari wawancara kegiatan yang dilakukan Jujur Ministry, menyusun desain kegiatan dan dokumen akuntansi, serta menyusun desain laporan keuangan untuk Jujur Ministry. Tahapan terakhir tim pengabdi melakukan presentasi hasil
\end{abstract}

kepada pendiri Jujur Ministry. Hasil dari pengabdian masyarakat ini berupa desain poster kegiatan yang dilakukan, desain dokumen akuntansi untuk kegiatan yang dilakukan, dan desain laporan keuangan yang disusun untuk Jujur Ministry. Tim pengabdi berharap pengabdian yang sudah dilakukan dapat membantu pendiri Jujur Ministry dalam mempertanggungjawabkan keuangan dan kegiatan yang dilakukan kepada para donatur secara transparan.

Kata kunci-dokumen, laporan keuangan, dan transparansi.

Abstract - The current Covid-19 pandemic has an impact on the state of the Indonesian economy, even affecting the economic life of the Indonesian people. Many Indonesians today have lost their jobs and live below the poverty line. Jujur Ministry was founded with the intention of helping people affected by Covid 19 by providing free breakfast for the underprivileged, and in the long term has plans to provide assistance in the field of education and home renovation. The founder of Jujur Ministry has a desire to have transparent financial reporting records to provide accountability to donors. The culture of honesty and a sense of humanity that underlies the holding of community service to Jujur Ministry. The purpose of community service carried out by the service team consisting of lecturers of the Accounting Study Program at the Business Faculty of Maranatha Christian University is to assist in the design of activities, accounting documents and 
financial reports for Jujur Ministry. Community service uses the interview method to the founder of Jujur Ministry and is carried out in stages starting from interviewing activities conducted by Jujur Ministry, compiling activity design and accounting documents, and compiling financial reports for Jujur Ministry. The last stage of the service team was to present the results to the founder of Jujur Ministry. The results of this community service are in the form of poster designs for activities carried out, accounting documents design for activities carried out, and financial reports prepared for Jujur Ministry. The service team hopes that the dedication that has been carried out can help the founder of Jujur Ministry in being accountable for the finances and activities carried out to the donors in a transparent manner.

Keywords - document, financial reports, and transparency.

\section{Pendahuluan}

Situasi Pandemi Covid-19 yang saat ini melanda beberapa negara, termasuk Indonesia dirasakan berdampak terhadap kehidupan perekonomian dan kesejahteraan masyarakat secara umum. Beberapa bantuan sosial dilakukan untuk menolong masyarakat yang merasakan dampak Pandemi Covid-19, terutama pada masa pemberlakuan pembatasan kegiatan masyarakat (PPKM). Indonesia Curruption Watch (ICW) mengingatkan pemerintah dalam hal pemberian bantuan sosial agar tidak terjadi potensi tindakan korupsi dalam penyaluran bantuan tersebut. Peneliti Pelayanan Publik dan Reformasi Birokrasi ICW mengatakan bahwa supaya tidak terjadi korupsi dalam penyaluran bantuan maka harus dilakukan secara transparan dan akuntabel (Iswinarno, Chandra dan Novian Ardiansyah, 2021).

Komisi Pemberantasan Korupsi (KPK) juga mengingatkan seluruh pihak untuk tidak mengambil keuntungan pribadi dalam penyaluran bantuan sosial seiring diberlakukannya Pemberlakuan Pembatasan Kegiatan Masyarakat (PPKM) Darurat di Pulau Jawa dan Bali yang dilaksanakan pada tanggal 3 sampai dengan 20 Juli 2021. KPK mengingatkan pemerintah untuk penyaluran bantuan sosial Covid-19 tetap dilakukan dengan mengedepankan prinsip transparansi dan akuntabel (Sitompul, Gary David, 2021).

Pengabdian masyarakat yang dilakukan oleh tim dosen Program Studi Akuntansi Universitas Kristen Maranatha dilakukan kepada Jujur Ministry yang merupakan salah satu pemberdayaan nilai-nilai kearifan lokal. Menurut (Hapsari, Jessica Amalia, 2021) salah satu tujuan pemberdayaan adalah untuk memperbaiki kehidupan untuk kesejahteraan masyarakat atau untuk pendidikan yang layak.

Jujur Ministry merupakan sebuah organisasi nirlaba yang baru didirikan pada bulan April 2021 dilatarbelakangi oleh keinginan pendiri untuk melakukan kegiatan sosial bagi masyarakat yang terdampak Pandemi Covid-19. Kegiatan sosial yang sudah dilakukan oleh Jujur Ministry berupa pemberian sarapan gratis dan pemberian paket lebaran yang dilaksanakan pada bulan April dan bulan Mei 2021. Pendiri Jujur Ministry ke depannya mengharapkan pencatatan akuntansi yang transparan sehingga semua kegiatan sosial yang dilakukan dapat dipertanggungjawabkan secara transaparan kepada donatur yang terlibat. Oleh karena itu pendiri Jujur Ministry meminta bantuan kepada Program Studi Akuntansi Universitas Kristen Maranatha untuk membuatkan penyusunan laporan keuangan yang transparan termasuk dokumen-dokumen akuntansi pendukungnya.

Jujur Ministry merupakan organisasi nirlaba/ entitas nirlaba yang melakukan beberapa kegiatan sosial di masa pandemic Covid-19. Tujuan organisasi nirlaba adalah untuk kesejahteraan sosial masyarakat, dengan sumber pembiayaan berasal dari donasi, serta bentuk laporan/pertanggungjawaban kepada publik/donatur (Nugroho, Dian Ari, 2017). Entitas nirlaba memperoleh sumber daya dari pemberi sumber daya dan tidak mengharapkan pembayaran kembali yang sebanding dengan jumlah sumber daya yang diberikan (Ikatan Akuntan Indonesia, 2018). Dalam organisasi nirlaba/nonprofit harus memiliki sistem pengelolaan keuangan yang baik dan transparan karena indikator keberhasilan sebuah lembaga adalah adanya transparansi dan akuntabilitas (Sagala, Syaiful, 2017).

Tim pengabdi Program Studi Akuntansi Universitas Kristen Maranatha melakukan kegiatan pengabdian masyarakat dalam bentuk pembuatan desain poster kegiatan Jujur Ministry, pembuatan dokumen akuntansi, dan pembuatan desain penyusunan laporan keuangan. Kegiatan pengabdian masyarakat ini dilakukan oleh dosen Program Studi Akuntansi dan mahasiswa Program Studi Sarjana Akuntansi, yang dilaksanakan selama dua bulan.

\section{TINJAUAN TEORETIS}

\section{A. Organisasi Nirlaba}

Organisasi nonprofit berfokus pada mencari dan mengalokasikan sumber daya untuk menyelesaikan pekerjaannya. Tujuan organisasi nonprofit adalah untuk meningkatkan kesejehteraan masyarakat tanpa mendapatkan keuntungan (Dropkin, Murray and James Halpin, 2005). Organisasi nirlaba menurut PNPM Mandiri adalah organisasi yang tujuan utamanya adalah mendukung atau terlibat aktif dalam aktivitas publik tanpa mencari keuntungan komersial (Sagala, Syaiful, 2017).

Entitas berorientasi non laba berbeda dengan entitas berorientasi laba dalam hal memperoleh sumber daya yang diperlukan untuk melakukan kegiatan aktifitas operasinya. Entitas nirlaba memperoleh sumber daya dari pemberi sumber daya yang tidak mengharapkan pembayaran kembali atau manfaat ekonomik yang sebanding dengan jumlah sumber daya yang diberikan. Entitas nirlaba 
memiliki kepentingan untuk menilai cara manajemen melakukan tanggung jawab atas penggunaan sumberdaya yang dipercayakan kepada mereka dan informasi mengenai posisi keuangan, kinerja keuangan, dan arus kas entitas yang bermanfaat dalam pembuatan keputusan ekonomik (Ikatan Akuntan Indonesia, 2018).

\section{B. Ciri Organisasi Nirlaba}

Ciri khas organisasi nirlaba adalah (Sagala, Syaiful, 2017): 1) bersifat sosial dan kemanusiaan; 2) badan sosial yang bukan bergerak untuk mencari laba; 3) sumber daya berasal dari penyumbang yang tidak mengharapkan pembayaran kembali atas sumber daya yang sudah diberikan; 4) alat untuk mencapai tujuan dari sekelompok orang yang memilikinya; 5) menghasilkan barang atau jasa yang jika memperoleh laba tidak pernah dibagikan kepada pendiri organsisasi; 6) tidak ada kepemilikan seperti organisasi bisnis.

Beberapa hal yang dipertimbangkan untuk menentukan apakah termasuk ke dalam organisasi berorientasi nonprofit adalah: 1) sumber daya berorientasi nonlaba berasal dari pemberi sumber daya yang tidak mengharapkan pembayaran kembali; menghasilkan barang/jasa tanpa tujuan memupuk laba; dan 3) tidak ada kepemilikan seperti entitas bisnis berorientasi laba yang artinya kepemilikan tidak dapat dijual, dialihkan atau ditebus kembali (Ikatan Akuntan Indonesia, 2018).

\section{Laporan Keuangan Organisasi Nirlaba}

Laporan keuangan menyediakan informasi tentang sumber daya ekonomik entitas pelapor, klaim terhadap entitas pelapor, dan dampak dari transaksi dan peristiwa serta kondisi lainnya yang mengubah sumber daya tersebut (Ikatan Akuntan Indonesia, 2019). Financial Accounting Standard Board (FASB) di Amerika telah menyusun laporan keuangan yang ditujukan bagi para pemilik entitas dan pihak lain yang tidak secara aktif terlibat dalam manajemen entitas bersangkutan, termasuk menyusun standar akuntansi bagi entitas nirlaba (Sagala, Syaiful, 2017). Organisasi Nonprofit didirikan untuk menyelesaikan misi khusus tertentu, dimana uang merupakan salah satu sumber daya yang digunakan. Bagaimana dana dikumpulkan dan digunakan tergantung beberapa faktor seperti kebutuhan suatu komunitas, kejadian yang terjadi saat ini, perencanaan keuangan, penganggaran, dan cash flow forecasting (Dropkin, Murray and James Halpin, 2005).

Laporan keuangan merupakan ringkasan proses pencatatan transaksi -transaksi keuangan yang terjadi selama periode pelaporan dan merupakan informasi yang dibutuhkan oleh pihak-pihak yang berkepentingan. Tujuan penyusunan laporan keuangan untuk memberikan informasi posisi keuangan perusahaan, kinerja dan arus kas perusahaan yang bermanfaat bagi pengguna laporan keuangan untuk membuat keputusan, serta merupakan bentuk pertanggungjawaban manajemen atas sumber daya yang digunakan (Bahri, Syaiful, 2016).

Laporan keuangan organisasi nonprofit terdiri dari laporan posisi keuangan, laporan aktivitas, laporan arus kas, dan catatan atas laporan keuangan. Tujuan utama laporan keuangan adalah menyediakan informasi yang relevan untuk memenuhi kepentingan penyumbang, anggota pengelola, kreditor, dan pihak lain yang menyediakan sumber bagi organisasi nonprofit. Secara rinci, tujuan laporan keuangan adalah menyajikan informasi mengenai: 1) Jumlah dan sifat aktiva, kewajiban, serta aktiva bersih;2) pengaruh transaksi atau peristiwa terhadap aktiva bersih; 3) jenis dan jumlah arus masuk dan arus keluar sumber daya; 4) cara mendapatkan dan membelanjakan kas serta faktor lain terkait likuiditas; dan 5) usaha jasa yang dilakukan (Bastian, Indra, 2007).

\section{Kelemahan Organisasi Nirlaba}

Organisasi nirlaba di Indonesia berkembang cukup pesat di bidang keagamaan, pendidikan, advokasi, kesehatan, profesi dan sebagainya, tetapi sayangnya tidak terlalu memperhatikan pentingnya sistem pengelolaan keuangan. Kelemahan organisasi nirlaba di Indonesia adalah tidak fokusnya pada misi, tujuan dan sasaran yang sudah dirancang. Oleh karena itu diperlukan sistem pengelolaan keuangan yang baik dan transparan karena diyakini menjadi salah satu indikator utama keberhasilan, akuntabilitas dan transparansi sebuah lembaga (Sagala, Syaiful, 2017).

\section{TAHAPAN PENGABDIAN MASYARAKAT}

\section{A. Tahap Wawancara}

Tim pengabdi Program Studi Akuntansi Universitas Kristen Maranatha pada tahap awal melakukan wawancara dengan pendiri Jujur Ministry untuk mengetahui kegiatan yang dilakukan oleh Jujur Ministry dan mengetahui kebutuhan apa yang diperlukan oleh Jujur Ministry. Wawancara dilakukan dengan media zoom untuk mengetahui latar belakang dan kegiatan Jujur Ministry.

Pada bagian berikutnya akan dibahas hasil dari wawancara kepada pendiri Jujur Ministry. Jujur Ministry didirikan oleh Henny Liana,S.Th. pada bulan April 2021. Jujur Ministry merupakan sebuah organisasi yang bergerak di bidang kemanusiaan dan tidak berorientasi profit atau termasuk organisasi nonprofit. Visi Jujur Ministry adalah melayani dengan kasih sesuai perintah kerajaan Allah dan menjadi perpanjangan Tuhan untuk orang miskin. Sedangkan misi Jujur Ministry adalah membantu mensejahterakan masyarakat yang miskin dan membangkitkan empati untuk orang tua dan anak-anak 
muda untuk terus memiliki gaya hidup berbagi dan memiliki hati yang berkemurahan.

Beberapa kegiatan sosial yang sudah dilakukan oleh Jujur Ministry adalah kegiatan pembagian sarapan gratis dan kegiatan pemberian paket lebaran yang sudah mulai dilakukan di bulan April sampai dengan bulan Mei. Jujur Ministry juga memiliki usaha penjualan kayu putih yang keuntungan penjualannya disumbangkan sepenuhnya kepada Jujur Ministry. Langkah selanjutnya yang akan dilakukan adalah membantu anak-anak untuk bersekolah khususnya untuk anak-anak yang berada di tingkat sekolah dasar.

Kondisi Jujur Ministry yang baru didirikan memerlukan transparansi terkait dengan pengumpulan dana dan penggunaan dana, sehingga tim pengabdi Prodi Akuntansi melakukan beberapa kegiatan terkait dengan pelaporan keuangan khususnya untuk membantu Jujur Ministry memberikan pertanggungjawaban keuangan kepada para donatur yang ikut serta dalam kegiatan sosial tersebut.

\section{B. Tahap Penyusunan Desain}

Tahap selanjutnya yang dilakukan oleh tim pengabdi Program Studi Akuntansi Universitas Kristen Maranatha adalah melakukan penyusunan desain kegiatan Jujur Ministry, penyusunan desain dokumen akuntansi untuk mendukung pencatatan kegiatan Jujur Ministry, dan penyusunan desain laporan keuangan untuk Jujur Ministry. Pembuatan desain dibantu oleh mahasiswa Program Studi Akuntansi Universitas Kristen Maranatha.

Berikut ini adalah hasil desain kegiatan pengabdian masyarakat yang sudah dilakukan oleh tim pengabdi Program Studi Akuntansi Universitas Kristen Maranatha, beserta dengan produk yang dihasilkan:

1. Desain kegiatan sosial Jujur Ministry

Kegiatan sosial yang dilakukan oleh Jujur Ministry berikutnya akan dipublikasikan kepada masyarakat melalui media sosial Instagram. Berikut ini adalah hasil desain kegiatan sosial yang dilakukan oleh Jujur Ministry:
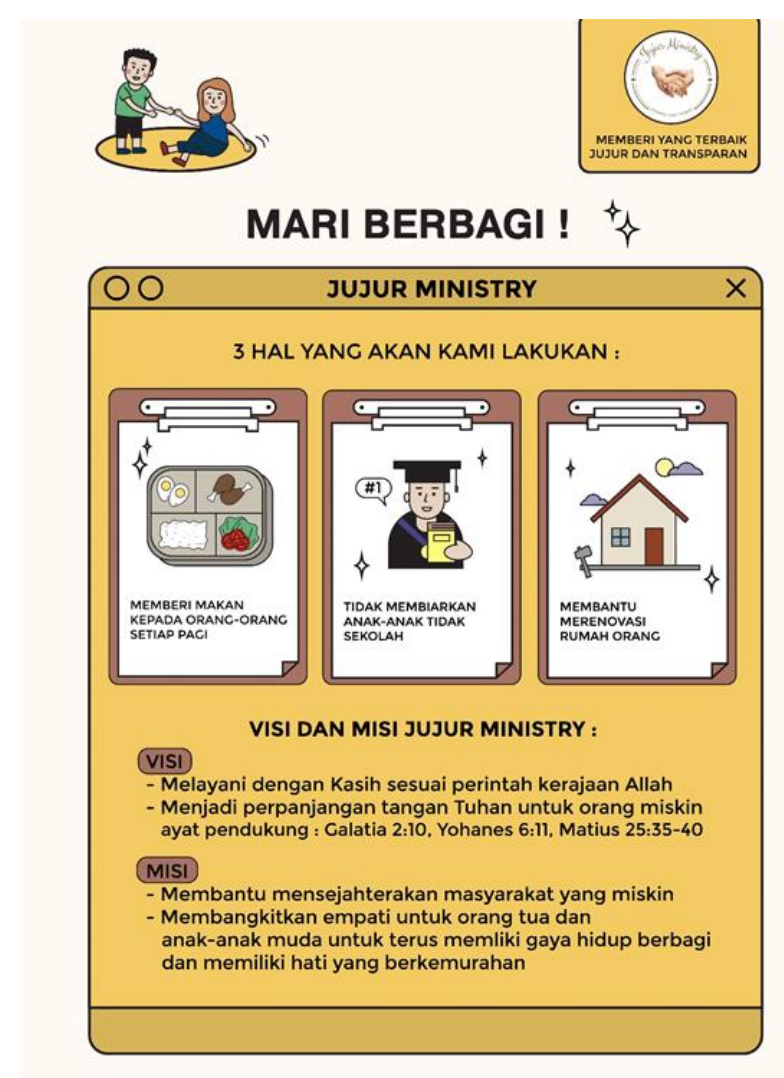

MULAI DARI YANG KECIL, BERLIMPAH LIMPAH BAGI ORANC LAIN

Gambar 1. Desain Jujur Ministry

2. 2. Desain penjualan minyak kayu putih

Jujur Ministry melakukan kegiatan usaha penjualan minyak kayu putih, hanya sebelumnya belum ada kegiatan publikasi penjualan minyak kayu putih tersebut sehingga tim dosen pengabdi membuatkan desain untuk penjualan minyak kayu putih untuk disimpan dan dipublikasikan di media sosial. Berikut ini adalah desain untuk minyak kayu putih: 


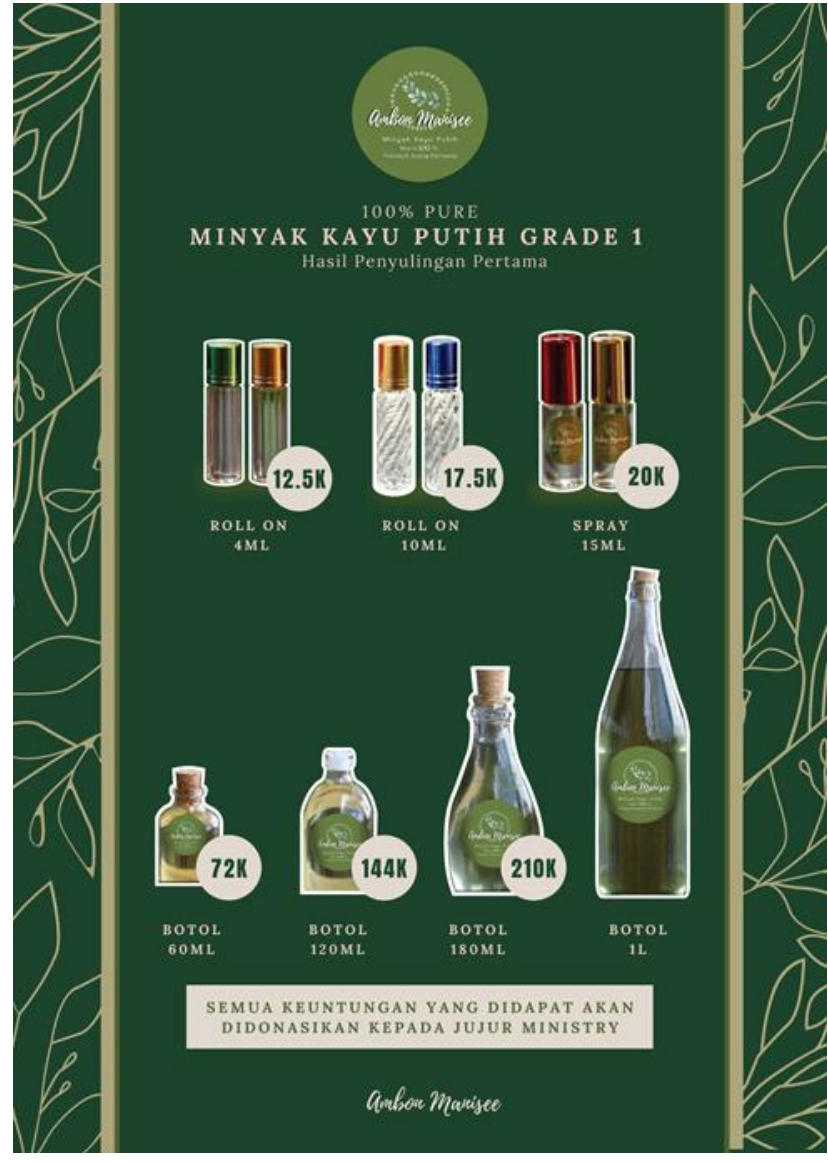

Gambar 2. Desain Penjualan Jujur Ministry

3. Desain dokumen donasi atau dokumen penjualan minyak kayu putih

Pengumpulan dana sumbangan dari donatur harus disertai dengan kwitansi yang akan diberikan kepada donatur sebagai bukti bahwa uang sudah diterima dan juga dibuatkan bon penjualan untuk penjualan minyak kayu putih sebagai salah satu usaha dari Jujur Ministry. Berikut ini adalah desain dokumennya:

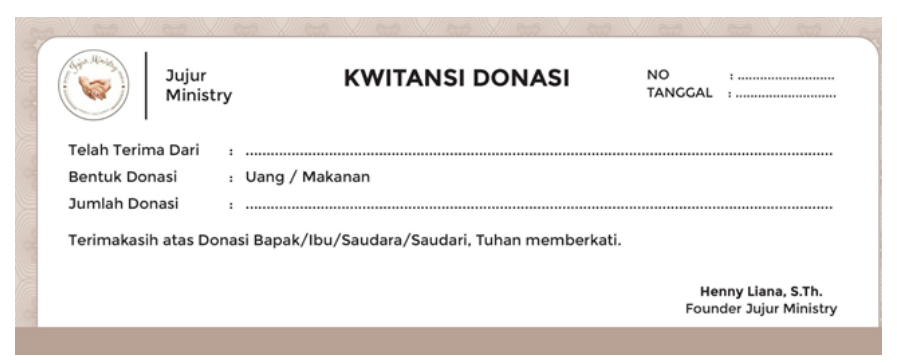

Gambar 3. Desain Kwitansi Donasi

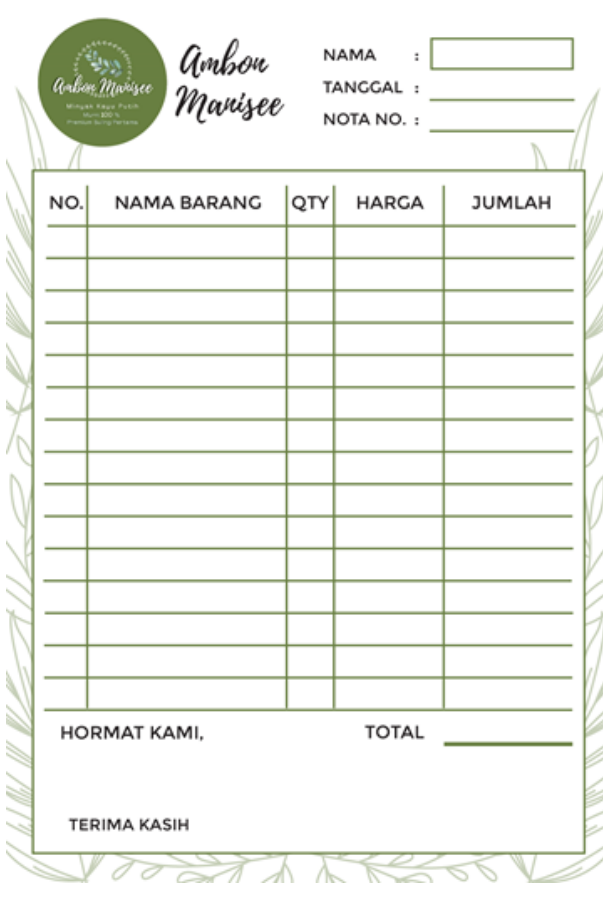

Gambar 4. Desain Faktur Penjualan

4. Rancangan penyusunan laporan keuangan Selain dokumen agar kegiatan sosial lebih transparan dan akuntabel, maka tim pengabdi membuatkan desain penyusunan laporan keuangan yang ke depannya diharapkan dapat digunakan oleh Jujur Ministry. Berikut ini adalah perancangan laporan keuangan Jujur Ministry:

$$
\text { TABEL I }
$$

Desain Laporan KeUANGAN JUJUR MinistRy

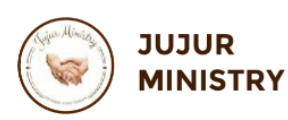

\section{LAPORAN PENDAPATAN DAN BEBAN UNTUK TAHUN YANG BERAKHIR .....}

\begin{tabular}{l}
\hline PENERIMAAN PENDAPATAN \\
Donasi \\
Penjualan Minyak Kayu Putih \\
Pendapatan Lain-lain \\
Pendapatan Bunga \\
\hline JUMLAH PENERIMAAN \\
\hline BEBAN PENGELUARAN \\
Bantuan Sarapan Gratis \\
Bantuan Pendidikan \\
Bantuan Lain-lain \\
Beban Operasional \\
Beban Administrasi Bank \\
\hline JUMLAH PENGELUARAN
\end{tabular}




\begin{tabular}{l} 
JUJUR \\
MINISTRY \\
LAPORAN PERUBAHAN ASET BERSIH \\
TAHUN YANG BERAKHIR ..... \\
\hline ASET \\
Kas dan Bank \\
Piutang \\
Uang Muka \\
\hline JUMLAH ASET \\
LIABILITAS \\
Liabilitas Lain-lain \\
JUMLAH LIABILITAS
\end{tabular}

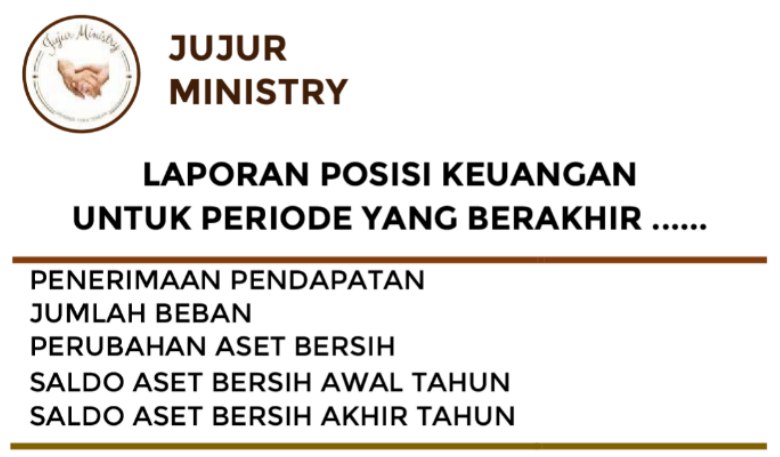

\begin{tabular}{l} 
JUJUR \\
MINISTRY \\
LAPORAN ARUS KAS \\
UNTUK PERIODE YANG BERAKHIR ...... \\
\hline PENERIMAAN \\
Penerimaan dari Donator \\
Penerimaan dari Piutang dan \\
Uang Muka \\
Penjualan Minyak Kayu Putih \\
Total Penerimaan \\
PENGELUARAN \\
Penyaluran Donasi Sarapan \\
Penyaluran Donasi Uang \\
Sekolah \\
Biaya Pengantaran \\
Total Pengeluaran \\
\hline TOTAL ARUS KAS \\
\hline
\end{tabular}

\section{Tahap Presentasi dan Pelaporan}

Tahap terakhir yang dilakukan oleh Tim pengabdi Program Studi Akuntansi Universitas Kristen Maranatha adalah mempresentasikan hasil desain yang sudah dikerjakan sebelumnya. Presentasi disampaikan dengan menggunakan media zoom dengan mendengarkan masukan dari pendiri Jujur Ministry. Setelah hasil desain dipresentasikan, maka tim Pengabdi Program Studi Akuntansi Universitas Kristen Maranatha membuatkan laporan kegiatan abdimas untuk dilaporkan kepada LPPM dan semua desain diberikam kepada pendiri Jujur Ministry untuk digunakan dalam kegiatan Jujur Ministry yang sedang berjalan, yang diharapkan dapat mewujudkan pertanggungjawaban laporan keuangan yang transparan.

\section{KESIMPULAN}

Tim Pengabdi Program Studi Akuntansi Universitas Kristen Maranatha sudah melakukan kegiatan pengabdian masyarakat kepada Jujur Ministry dalam bentuk pembuatan desain kegiatan sosial yang dilakukan Jujur Minsitry, pembuatan desain salah satu usaha yang dilakukan oleh Jujur Ministry yaitu penjualan minyak kayu putih, pembuatan atau perancangan dokumen akuntansi, dan perancangan laporan keuangan. Tim pengabdi berharap dengan kegiatan pengabdian yang sudah dilakukan dapat membantu Jujur Ministry dalam mempertanggungjawabkan kegiatan sosial yang sudah dilakukan, khususnya dalam hal pengumpulan dana dan penggunaan dana yang transparan dan akuntabel kepada para pemberi sumbangan atau donatur yang terlibat dalam kegiatan sosial yang dilakukan oleh Jujur Minsitry.

Refleksi dari proses dan hasil kegiatan pengabdian masyarakat kepada Jujur Ministry ini adalah membentuk budaya jujur dan transparan melalui pembuatan desain dokumen akuntansi dan laporan keuangan, sehingga semua kegiatan yang dilakukan oleh Jujur Ministry dapat dipertanggungjawabkan kepada donatur. Pengabdian masyarakat kepada Jujur Ministry merupakan kegiatan pengabdian yang berkelanjutan, yang mana selanjutnya akan dilakukan penyusunan laporan keuangan Jujur Ministry berdasarkan kegiatan sosial yang dilakukan dan berdasarkan bisnis yang sudah dilakukan oleh Jujur Ministry.

\section{UCAPAN TERIMA KASIH}

Kegiatan pengabdian masyarakat ini terselenggara atas kerjasama beberapa pihak, tim pengabdi secara khusus berterima kasih kepada:

1. Ibu Henny Liana, S.Th. selaku pendiri Jujur Ministry yang telah memberikan kesempatan kepada kami untuk memberikan pengabdian kepada masyarakat untuk mendukung kegiatan Jujur Ministry dalam hal transparansi keuangan. 
2. Universitas Kristen Maranatha, khususnya LPPM yang telah memberikan kesempatan kepada tim dosen pengabdi Sarjana Akuntansi untuk menyelenggarakan dan memberikan dukungan dana untuk menyelenggarakan kegiatan pengabdian masyarakat ini.

\section{DAFTAR PUSTAKA}

[1] Bahri, Syaiful. (2016). Pengantar Akuntansi Berdasarkan SAK ETAP dan IFRS. Yogyakarta: Andi.

[2] Bastian, Indra. (2007). Akuntansi Yayasan dan Lembaga Publik. Jakarta: Erlangga.

[3] Dropkin, Murray and James Halpin. (2005). Bookkeeping for Nonprofits. San Fransisco: John Wiley \& Sons, Inc.

[4] Hapsari, Jessica Amalia. (2021, Februari 25). Arti Kearifan Lokal di Indonesia: Nilai, Dimensi, Contoh dan Fungsi. Retrieved from tirto.id: https://tirto.id/arti-kearifan-lokal-di-indonesia-nilaidimensi-contoh-fungsi-gadt
[5] Ikatan Akuntan Indonesia. (2018). ISAK 35: Penyajian Laporan Keuangan Entitas Berorientasi NonLaba. Jakarta: Ikatan Akuntan Indonesia.

[6] Ikatan Akuntan Indonesia. (2019). Standar Akuntansi Keuangan. Jakarta: Ikatan Akuntan Indonesia.

[7] Iswinarno, Chandra dan Novian Ardiansyah. (2021, Juli 6). Korupsi Kecil-Kecilan Jadi Masalah, ICW Minta Pemerintah Tingkatkan Transparansi Bansos. Retrieved from www.suara.com:

https://www.suara.com/news/2021/07/06/150023/korupsi-

kecil-kecilan-jadi-masalah-icw-minta-pemerintah-tingkatkantransparansi-bansos?page $=$ all

[8] Nugroho, Dian Ari. (2017). Pengantar Manajemen untuk Organisasi Bisnis, Publikn dan Nirlaba. Yogyakarta: UB Press.

[9] Sagala, Syaiful. (2017). Human Capital: Membangun Modal Sumber Daya Manusia Berkarakter Unggul Melalui Pendidikan Berkualitas. Jakarta: Kencana.

[10] Sitompul, Gary David. (2021, Juli 3). Penyaluran Bansos PPKM, KPK: Harus Transparan dan Akuntabel. Retrieved from www.jurnas.com:

https://www.jurnas.com/artikel/95563/Penyaluran-BansosPPKM-KPK-Harus-Transparan-dan-Akuntabel/ 